\title{
Clinicoepidemiologic factors that affect the number of rehospitalizations in the psychiatric department of a general hospital \author{
George Kaprinis
} \\ Stamatia Magiria*, Konstantinos Fountoulakis, Apostolos Iacovides and
}

Address: 3rd Department of Psychiatry, Aristotle University of Thessaloniki, Greece

* Corresponding author

from International Society on Brain and Behaviour: 2nd International Congress on Brain and Behaviour

Thessaloniki, Greece. 17-20 November 2005

Published: 28 February 2006

Annals of General Psychiatry 2006, 5(Suppl I):S33I doi:I0.1186/I744-859X-5-SI-S33 I

\section{Background \\ During the last few years, an important question concerns how it is possible to reduce the number of hospitaliza- tions and keep the patients in a good condition and as much as possible in the community. The aim of our study was the evaluation of the relationship between clinicode- mographic characteristics of inpatients of Psychiatric Department of General Hospital and hospitalization parameters.}

\section{Materials and methods}

The study sample included 100 consecutive inpatients of the 3rd Department of Psychiatry, AUTh. The age, diagnosis, age of onset of the illness, number of hospitalizations and number of visits in outpatient clinic after hospitalization were registered.

\section{Results}

Forty eight were male and 52 female. In terms of insurance, 14 had public servant insurance, 39 had social insurance, 13 had agricultural insurance and 10 welfare. The rest had other type of insurance. In terms of diagnosis, 25 suffered from schizophrenia, 27 from unipolar depression, 10 from bipolar disorder, 14 from other psychotic disorders and 5 from vascular dementia. There were also some less prevalent diagnosis present. Their age was 46.06 \pm 15.12 years. The age and age of onset did not correlate with the number of hospitalizations. There was no significant difference between genders and among different insurance organizations in terms of age, age of onset or number of hospitalizations ( $\mathrm{p}>0.1)$. Diagnosis played a major role concerning the number of hospitalizations ( $p$ $<0.01$ ) but this was exclusively because patients with schizophrenia were significantly younger $(37.5 \pm 4.41$ years vs. $48.3 \pm 4.39$ and $49.57 \pm 5.28$ ), with a younger age of onset in comparison to both unipolar and bipolar patients $(24.8 \pm 3.97$ years vs. $41.1 \pm 3.96$ and $34.86 \pm$ $4.75)$ and also had less hospitalizations $(3.4 \pm 0.74$ vs. 4.2 \pm 0.73 and $6 \pm 0.89$ ). The pattern of hospitalizations appears to differ between diseases. Schizophrenic patients tend to manifest a peak before the age of 40; afterwards the rate of hospitalizations decline. In contrast, bipolar patients manifest a peak around the age of 50 and retain a high rate afterwards. The accurate statistic analysis of the relationship between the number of hospitalizations and the number of patients examined after hospitalization, wasn't possible because of the very small number of patients re-examined in outpatient clinic.

\section{Discussion}

The results of the current study suggest that in the Greek reality, the major predictor for the number and pattern of hospitalizations and consequently the 'revolving door phenomenon' is diagnosis. The general medical care system and other socio-economical and demographic variables play a much weaker role. The above point to the need for the development of new therapies but also for targeting the specific characteristics (e.g. aging, vascular problems) that may determine the pattern of hospitalizations of mental patients across the life span. 